\title{
The direction of effects between perceived parental behavioral control and psychological control and adolescents' self-reported GAD and SAD symptoms
}

\author{
Saskia A. M. Wijsbroek • William W. Hale III • \\ Quinten A. W. Raaijmakers · Wim H. J. Meeus
}

Received: 8 July 2010/Accepted: 1 May 2011/Published online: 22 May 2011

(C) The Author(s) 2011. This article is published with open access at Springerlink.com

\begin{abstract}
This study examined the direction of effects and age and sex differences between adolescents' perceptions of parental behavioral and psychological control and adolescents' self-reports of generalized anxiety disorder (GAD) and separation anxiety disorder (SAD) symptoms. The study focused on 1,313 Dutch adolescents (earlyto-middle cohort $n=923,70.3 \%$; middle-to-late cohort $n=390,29.7 \%$ ) from the general population. A multigroup, structural equation model was employed to analyze the direction of the effects between behavioral control, psychological control and GAD and SAD symptoms for the adolescent cohorts. The current study demonstrated that a unidirectional child effect model of the adolescents' GAD and SAD symptoms predicting parental control best described the data. Additionally, adolescent GAD and SAD symptoms were stronger and more systematically related to psychological control than to behavioral control. With regard to age-sex differences, anxiety symptoms almost systematically predicted parental control over time for the early adolescent boys, whereas no significant differences were found between the late adolescent boys and girls.
\end{abstract}

Keywords Adolescent - Behavioral control . Effect model · Generalized anxiety disorder . Psychological control - Separation anxiety disorder

S. A. M. Wijsbroek $(\bowtie) \cdot$ W. W. Hale III ·

Q. A. W. Raaijmakers - W. H. J. Meeus

Research Center Adolescent Development, Utrecht University, 80.140, 3508 TC Utrecht, The Netherlands

e-mail: s.a.m.wijsbroek@uu.nl

\section{Introduction}

In an attempt to better understand the effects parenting practice characteristics have on the development and maintenance of adolescent anxiety, several theoretical models have been proposed $[9,26,56,61,74]$ that try to explain the findings of recent studies that indicate that parenting characteristics differ between families with high levels of anxiety and non-anxious families [21, 28, 32, 84]. Parental control is considered one of the most important of these parenting characteristics [83].

Literature reviews of empirical studies on parental control have demonstrated that parental controlling behaviors and adolescent anxiety are significantly related to one another $[21,53,55]$. Studies of parents with anxious children and adolescents have shown that these parents use significant more controlling behaviors; however, most of these previous studies have been cross-sectional as opposed to longitudinal. Therefore, one of the most important questions remains the direction of effects parental control and child anxiety have on one another [21, 44]. Knowledge as to the direction of effects is needed in the development of evidence-based interventions [21].

In a review of the literature of the direction of effects in parent-adolescent interactions, Branje, Hale and Meeus [25] discussed three of the most prominent models [43]. The first model, the parent effect model, assumes that specific parental behavior has a major influence on individual adolescent problem behavior; in other words, parental control eliciting adolescent anxiety. It is suggested that severe parental control leads to child perceptions of the environment as uncontrollable, resulting in non-adequate coping behavior and anxiety in children and adolescents and preventing the adolescent from acquiring developmental-appropriate behaviors $[14,21,27,31,56]$. The 
adolescent remains dependent of his or her parents, which can lead to anxiety disorder symptoms such as separation anxiety disorder (SAD) symptoms [14, 83].

The second model, the child effect model, supposes that a child's characteristics are influential in shaping parental behavior [17, 18, 41, 51]. According to this model, adolescent anxiety elicits severe parental control. An adolescent with a temperament characterized by high arousal and emotionality may elicit increased parental control and over-involvement as the parents attempt to reduce the adolescent's stress while adapting to the sensitivity of their adolescent in specific situations. Conversely, negative emotional appeals from the anxious adolescent can lead to parents becoming less sensitive and more demanding in accommodating their child's demands [21, 31, 56, 61].

The final model, the reciprocal effects model, emphasizes the bi-directionality of effects in which children and parents influence each other and contribute to each other's individual developmental outcomes [17, 43, 62]. According to this model, severe parental control and adolescent anxiety reciprocally affect each other, adolescent anxiety eliciting changes in parental control and parental control influencing adolescent anxiety [52].

With respect to the direction of the effects of parental control on adolescent anxiety and/or vice versa, no clearcut consensus has yet been reached [9, 13, 44, 52, 54]. Therefore, in light of the aforementioned models, the purpose of the current study is to explore the direction of effects between perceived parental control and adolescent anxiety disorder symptoms.

The parenting literature differentiates parental control into two constructs: parental behavioral control and parental psychological control [9, 10]. Research demonstrates that each construct has its own distinct impact on child outcomes $[12,67]$.

However, the differentiation of behavioral control and psychological control has been criticized. Recent studies and literature reviews have noted that behavioral control and psychological control and emotional and behavioral outcomes cannot be clearly distinguished $[34,69,76]$. It is suggested to define parental control as two dimensions of parenting: parental control and parental structure. Parental control is characterized by pressure, intrusiveness and dominance of the parents in relation to the adolescent' feelings, thoughts and behaviors. Parental structure is characterized by the organization of the adolescent environment to facilitate the adolescent's competence [34, 76].

Nevertheless, in a very recent study by Soenens and Vansteenkiste [69], the authors argue for the continuation of the differentiation of parental behavioral control and parental psychological control. They specifically argue that one form of parental control refers to the attempts of parents to regulate and structure the behavior of their child, in other words, parental behavioral control. They go on to suggest that this form of parental control is different from the second form of parental control that "...refer[s] to a controlling, pressuring or coercive parenting environment that controls children's feelings, thinking, and behaving" [69, p. 86], in other words, parental psychological control.

In light of the aforementioned, it is clear that this debate has been ongoing and has not yet come to a definitive conclusion. Since the goal of this study is to explore the direction of effects between perceived parental control and adolescent anxiety disorder symptoms with respect to the three aforementioned effect models, we believe using the more traditional approach of measuring parental control in light of behavioral control and psychological control will allow us to examine possible similarities and differences between the two.

Mechanisms explaining the relationship between adolescent anxiety and parental control have been based on models that characterized the role of personal control and self-efficacy as determinants of anxiety [e.g., 26, 44]. Different expressions of parental controlling behaviors (i.e., behavioral control and psychological control) result in the adolescent not mastering developmental tasks required to equip the adolescent to sufficiently deal with anxiety symptoms common to adolescent development. For example, parental behavioral control can lead the adolescent to a weak sense of self-efficacy, which in turn can lead to an increased vulnerability to developing anxiety disorder symptoms [26, 44], whereas parental psychological control can lead adolescents to develop a cognitive bias with perceptions of events as out of the adolescent's control, which, in turn, can also lead to an increased vulnerability to anxiety disorder symptoms [84].

With regard to the definition of behavioral control, Soenens and Vansteenkiste [69] criticized the term 'control' in behavioral control, since the term 'control' can be understood in two different ways. In the first place, control can refer to the attempts of parents to regulate and structure the behavior of their child. Secondly, control can refer to a controlling parenting environment $[69$, p. 86]. In the current study, parental behavioral control is defined as the adolescent's perception of both the provision of regulation and structuring and a controlling and pressuring parenting environment [69]. The exploration of the relationship between parental behavioral control and adolescent anxiety is based on the suggestion that, on the one hand, the adolescent's daily life in a controlling and pressuring environment [69] may contribute to adolescents' perceptions of the environment as uncontrollable and prevent growth of developmental-appropriate behaviors [14, 21, 26, 31, 57]. On the other hand, adolescent anxiety may elicit parental behavioral control in which the parents take on more decisions for their adolescent to provide safety and 
predictability for the adolescent [44]. This environment, created by parental behavioral control, can lead the adolescent to a weak sense of self-efficacy, which in turn can lead to an increased vulnerability to the development of anxiety disorder symptoms.

It should also be noted that in this study parental psychological control is defined as the intrusive and manipulative behaviors of parents (i.e., influence thoughts, feelings and attachment, associated with guilt induction and shaming) that hamper the development of independence and autonomy of their adolescents [10-12, 21]. Additionally, as mentioned, parental psychological control can lead adolescents to develop a cognitive bias of events as out of their control, which in turn can also lead to an increased vulnerability to anxiety disorder symptoms.

Perceived parental psychological control and adolescent depressive disorder symptoms as defined by the DSM-IVTR as internalizing problem behavior demonstrated a positive relationship in recent longitudinal research [68, 70]. However, the majority of the aforementioned studies of parental control and adolescent anxiety as internalizing problem behavior have focused on general adolescent anxiety symptoms, as opposed to specific DSMIV-TR anxiety disorder symptoms. Hence, longitudinal investigation of parental behavioral control and parental psychological control associated with specific types of DSM-IV-TR adolescent anxiety disorder symptoms [5] is presently lacking and is needed in order to better illuminate the relationship between perceived parental control and specific adolescent anxiety disorder symptoms. Of these specific adolescent anxiety disorders, two DSM-IV-TR anxiety disorders are specifically related to problematic parenting: generalized anxiety disorder (GAD) [35, 48, 55] and SAD [30].

GAD is one of the most commonly occurring adolescent anxiety disorders $[29,54,75,78,80]$ characterized by frequent, excessive worry $[5,6]$. Social-evaluative concerns were at the center of adolescent GAD worry symptoms [39, $79,81]$ and interpersonal problems with parents were found to be related to adolescent GAD symptoms [35, 46, 47, 73].

$\mathrm{SAD}$ as a syndrome is characterized by non-age appropriate and excessive anxiety regarding separation from caregivers or from home [5]. This means that an adolescent remains extremely dependent on his or her parents for his daily functioning in a phase in which growing independence is expected [79]. Extreme distress occurs when the adolescent is separated from attached persons [30].

Positive associations between perceived parental psychological control and GAD symptoms have been found in cross-sectional studies of pre-adolescents [48] and adolescents $[35,55]$. With respect to the association between perceived parental behavioral control and psychological control and adolescent SAD, to our knowledge no empirical studies have yet been conducted.

As noted, the goal of the present study is to investigate the direction of effects between perceived parental behavioral and psychological control and perceived adolescent GAD and SAD symptoms. Since consensus has not yet been formed as to which of the three models best explains parental behavioral and psychological control and adolescent GAD and SAD anxiety symptoms, no specific hypothesis of the direction of effects can be made. For the current study, age and gender differences between parental behavioral and psychological control and GAD and SAD symptoms will be explored. However, since parental behavioral and psychological control and adolescent GAD and SAD symptoms have not been studied together in one and the same research design in the past, no specific hypotheses can be formulated.

\section{Method}

\section{Participants}

The data for this study were collected as part of a largescale research project Conflict And Management $O$ f Relationships (CONAMORE) [45]. The longitudinal sample consisted of 1,313 participants divided into an early-to-middle adolescent cohort $(n=923 ; 70.3 \%)$, who were 12.4 years of age $(\mathrm{SD}=0.59)$ on average, and a middle-to-late adolescent cohort $(n=390 ; 29.7 \%)$ with an average age of 16.7 years $(\mathrm{SD}=0.80)$ during the first wave of measurement. Most participants identified themselves as being Dutch (84.9\%). Smaller proportions of participants identified themselves as belonging to various non-Western ethnic groups (15.1\%). Most participants lived with both parents $(84.9 \%)$, a minority lived with their mother $(10.7 \%)$, father $(1.4 \%)$ or someone else $(2.9 \%)$. Regarding educational level, around $60 \%$ of the participants were in pre-university or in preparatory higher professional education, and around $40 \%$ were in preparatory secondary vocational education. The early-tomiddle adolescent cohort consisted of 468 boys (50.7\%) and 455 girls (49.3\%), and the middle-to-late adolescent cohort consisted of 169 boys (43.3\%) and 221 girls $(56.7 \%)$. The cohorts did not differ in home situation, ethnic composition or educational level. Sample attrition was $1.2 \%$ across the three waves with a 2 -year interval between each of the waves: in waves 1,2 and 3 , the number of participants was 1,313, 1,293 and 1,275, respectively. Missing indicator item values were estimated in SPSS, using the EM procedure. 


\section{Procedure}

The adolescents who participated in this study completed the questionnaires during the homeroom study period, which lasted for an hour. Adolescents were informed of the research foregoing to this study and were given the opportunity not to participate. Prior to the study, both adolescents and parents received written information and, if the adolescent chose to participate, were required to provide written informed consent. Verbal instructions as to how to fill in the questionnaires were given to the adolescents by the research assistants just prior to the testing to complement the written instructions printed above each questionnaire. At the end of the homeroom study period, the research assistants collected the questionnaires. These assistants additionally conducted the data entry so as to insure that the data remained anonymous to the researcher.

\section{Measures}

\section{Perceived behavioral control and psychological control}

To measure perceived behavioral and psychological control, use was made of the scales 'behavioral control' and 'psychological control' of the Children's Reports of Parental Behaviour Inventory (CRPBI) [40, 63-65]. Both control scales of the CRPBI consist of ten items for each scale, with scores ranging from 0 (never) to 4 (always). Example questions are: "My parents are very strict with me" (behavioral control) and: "My parents do not look at me if I disappointed them" (psychological control). Confirmatory factor analyses demonstrated an acceptable fit with the data of the entire adolescent sample for behavioral control $\left(\chi^{2} / d f=3.33\right.$, GFI $=0.98, \mathrm{CFI}=0.99$, RMSEA $=0.04)$ as well as for psychological control $\left(\chi^{2} /\right.$ $d f=3.65$, GFI $=0.97$, CFI $=0.98$, RMSEA $=0.05)$. In this study, Cronbach's alphas across the waves were $0.65-0.77$ for the behavioral control scale and 0.86 and 0.87 for the psychological control scale.

\section{GAD symptoms and SAD symptoms}

To measure GAD and SAD symptom scores, the GAD and the SAD subscales of the screen for child anxiety-related emotional disorders (SCARED) were used. The SCARED is a self-report questionnaire, designed for children and adolescents, which measures the occurrence of anxiety disorder symptoms on a three-point Likert scale: 1 (almost never), 2 (sometimes), 3 (often) [19, 20]. The GAD symptom subscale consists of nine items. An example item for a GAD symptom is: "I worry about other people liking me". The SAD symptom subscale consists of eight items. An example item for a SAD symptom is: "I follow my mother or father wherever they go." Reliability [49] and construct validity of the SCARED are strong [37]. The GAD and SAD scales both have acceptable fits with the data of the entire sample tested in confirmatory factor analyses $\left(\mathrm{GAD}: \chi^{2} / d f=4.03, \mathrm{CFI}=0.99, \mathrm{RMSEA}=\right.$ 0.06; SAD: $\left.\chi^{2} / d f=3.17, \mathrm{CFI}=0.98, \mathrm{RMSEA}=0.05\right)$. Cronbach's alphas for the scale GAD across the three waves ranged from 0.82 to 0.86 and Cronbach's alphas for the scale SAD ranged from 0.67 to 0.77 .

\section{Data analysis}

In this study, a structural equation model based on maximum likelihood estimation was employed (AMOS) [7, 22] to examine the relationship between parental behavioral and psychological control and adolescent GAD symptoms over time, as well as parental behavioral and psychological control and adolescent SAD symptoms over time. The model fits were evaluated by means of three indices: the comparative fit index (CFI: a value of 0.95 or greater represents a good fit), the normed fit index (NFI: a value of 0.95 or greater represents a good fit) and the root mean square error of approximation (RMSEA: a value of 0.05 or less represents a good fit and a value of 0.08 or less is an acceptable fit) [42].

Analyses of the entire adolescent group and multi-group analysis were then conducted to explore the effects of age and sex of the adolescents. The four groups of the multigroup analysis were early adolescent boys $(n=468)$, early adolescent girls $(n=455)$, late adolescent boys $(n=169)$ and late adolescent girls $(n=221)$. Four different models were examined. First, a restricted model was tested in which all the estimated parameters were required to be equal across the four groups. Next, a second model was tested in which the estimated parameters were allowed to differ for the different age groups (i. e., early and late adolescents), and a third model in which the estimated parameters were allowed to differ for the sex groups. Finally, a fourth non-restricted model was tested in which all the parameters were allowed to differ across both age and sex cohorts. While structural equation modeling produces many different parameters, only the significant cross paths related to the study's examination of the effect models are discussed in "Results".

\section{Results}

\section{Descriptives}

The means and standard deviations of the entire adolescent group and the adolescent age and sex cohorts for perceived parental behavioral and psychological control and 
Table 1 Means and SD of the total adolescent group and age and sex groups for perceived behavioral control, perceived psychological control, perceived adolescent generalized anxiety disorder (GAD) symptoms and adolescent separation anxiety disorder (SAD) symptoms

\begin{tabular}{|c|c|c|c|c|c|}
\hline & $\begin{array}{l}\text { Entire adolescent group } \\
(n=1,313) M(\mathrm{SD})\end{array}$ & $\begin{array}{l}\text { Early adolescent boys } \\
(n=468) M(\mathrm{SD})\end{array}$ & $\begin{array}{l}\text { Early adolescent girls } \\
(n=455) M(\mathrm{SD})\end{array}$ & $\begin{array}{l}\text { Late adolescent boys } \\
(n=169) M(\mathrm{SD})\end{array}$ & $\begin{array}{l}\text { Late adolescent girls } \\
(n=221) M(\mathrm{SD})\end{array}$ \\
\hline Behavioral control T1 & $3.02(0.57)$ & $3.04(0.49)$ & $3.07(0.51)$ & $2.88(0.61)$ & $2.96(0.74)$ \\
\hline Behavioral control T2 & $2.95(0.57)$ & $3.01(0.47)$ & $3.08(0.56)$ & $2.73(0.61)$ & $2.70(0.64)$ \\
\hline Behavioral control T3 & $2.90(0.66)$ & $2.96(0.59)$ & $3.15(0.59)$ & $2.53(0.64)$ & $2.54(0.67)$ \\
\hline Psychological control T1 & $2.24(0.73)$ & $2.39(0.78)$ & $2.07(0.66)$ & $2.43(0.66)$ & $2.11(0.72)$ \\
\hline Psychological control T2 & $2.10(0.66)$ & $2.31(0.66)$ & $2.01(0.60)$ & $2.12(0.64)$ & $1.86(0.64)$ \\
\hline Psychological control T3 & $2.01(0.64)$ & $2.13(0.62)$ & $1.99(0.65)$ & $1.99(0.61)$ & $1.80(0.64)$ \\
\hline GAD symptoms $\mathrm{T} 1$ & $1.38(0.39)$ & $1.30(0.37)$ & $1.40(0.38)$ & $1.30(0.35)$ & $1.54(0.44)$ \\
\hline GAD symptoms T2 & $1.38(0.40)$ & $1.29(0.35)$ & $1.42(0.42)$ & $1.32(0.33)$ & $1.54(0.44)$ \\
\hline GAD symptoms T3 & $1.38(0.41)$ & $1.24(0.31)$ & $1.46(0.43)$ & $1.28(0.33)$ & $1.57(0.48)$ \\
\hline SAD symptoms $\mathrm{T} 1$ & $1.32(0.31)$ & $1.32(0.33)$ & $1.37(0.31)$ & $1.25(0.30)$ & $1.28(0.25)$ \\
\hline SAD symptoms $\mathrm{T} 2$ & $1.31(0.29)$ & $1.31(0.31)$ & $1.35(0.30)$ & $1.18(0.18)$ & $1.30(0.24)$ \\
\hline SAD symptoms T3 & $1.24(0.27)$ & $1.24(0.28)$ & $1.28(0.27)$ & $1.15(0.21)$ & $1.24(0.24)$ \\
\hline
\end{tabular}

adolescent GAD and SAD symptoms are presented in Table 1. In general, the mean scores of perceived parental behavioral and psychological control decreased systematically over time. For early adolescent girls, only the mean scores of parental behavioral control increased over all waves.

The mean scores of GAD symptoms were stable over time for the entire group. GAD mean scores decreased for early adolescent boys over all waves, increased for the late adolescent boys from the first to the third wave and decreased from the third to the fifth wave. GAD mean scores increased over all waves for early adolescent girls. For late adolescent girls, the mean scores of GAD symptoms were stable from the first to the third wave and increased from the third to the fifth wave. The mean scores of SAD symptoms decreased over time for the entire group: the early adolescent boys, early adolescent girls and late adolescent boys. For the late adolescent girls, only the mean scores of SAD symptoms increased form the first to the third wave and decreased from the third to the fifth wave.

Initial correlations, correlations of the stability paths and correlations of the cross paths have been computed for the total adolescent group and age and sex groups and are presented in Table 2.

Total group and multi-group SEM analyses

The model tested for the total adolescent group provided a good fit to the data for perceived parental behavioral control and adolescent GAD symptoms, $\chi^{2} / d f=1.12$, $\mathrm{NFI}=1.00, \mathrm{CFI}=1.00, \mathrm{RMSEA}=0.01$, and perceived parental behavioral control and adolescent SAD symptoms: $\chi^{2} / d f=4.46, \mathrm{NFI}=0.99, \mathrm{CFI}=1.00, \mathrm{RMSEA}=0.05$. The model provided an acceptable fit to the data for perceived parental psychological control and adolescent
GAD symptoms: $\chi^{2} / d f=7.73, \mathrm{NFI}=0.99, \mathrm{CFI}=0.99$, RMSEA $=0.07$; and perceived parental psychological control and adolescent SAD symptoms: $\chi^{2} / d f=7.50$, $\mathrm{NFI}=0.99, \mathrm{CFI}=0.99, \mathrm{RMSEA}=0.07$.

A non-restricted model that allowed for age and sex differences provided the best fit to the data. Specifically, the model fits for perceived parental behavioral control and adolescent GAD symptoms were $\chi^{2} / d f=0.77, \mathrm{CFI}=$ $1.00, \mathrm{NFI}=1.00$, RMSEA $=0.00 ;$ perceived parental behavioral control and adolescent SAD symptoms were $\chi^{2} /$ $d f=0.85, \quad \mathrm{CFI}=1.00, \quad \mathrm{NFI}=0.99 ; \quad \mathrm{RMSEA}=0.00 ;$ perceived parental psychological control and perceived adolescent GAD symptoms: $\chi^{2} / d f=2.93, \mathrm{CFI}=$ 0.99 , NFI $=0.99$, RMSEA $=0.04$; and perceived parental psychological control and perceived adolescent SAD symptoms: $\chi^{2} / d f=3.09, \mathrm{CFI}=0.99, \mathrm{NFI}=0.98$, RMSEA $=0.04$. For all four models, the $\chi^{2} / d f$ ratio, the CFI, NFI and the RMSEA of the final models were better than those of the restricted models and the non-restricted models that only allowed for either age differences or for sex differences.

Figure 1 represents the model for the entire adolescent group and the four non-restricted models that allowed for age and sex differences for perceived parental behavioral control and psychological control, and adolescent GAD and SAD symptoms, respectively. As noted in "Method", only the significant cross paths related to the study's examination of the effect models are presented.

Initial correlations and cross paths of behavioral control and GAD symptoms

The initial correlations at the first wave between behavioral control and GAD were only significant for the early 
Table 2 Pearson correlations for perceived parental behavioral control, perceived parental psychological control, perceived adolescent generalized anxiety disorder (GAD) symptoms and perceived adolescent separation disorder (SAD) symptoms of the total adolescent group and age and sex groups

\begin{tabular}{|c|c|c|c|c|c|}
\hline Parameter & Entire group & $\begin{array}{l}\text { Early } \\
\text { adolescent boys }\end{array}$ & $\begin{array}{l}\text { Early } \\
\text { adolescent girls }\end{array}$ & $\begin{array}{l}\text { Late } \\
\text { adolescent boys }\end{array}$ & $\begin{array}{l}\text { Late } \\
\text { adolescent girls }\end{array}$ \\
\hline \multicolumn{6}{|l|}{ Initial correlations } \\
\hline BcW1-GADW1 & 0.07 & 0.06 & $0.10^{*}$ & $0.16^{*}$ & 0.02 \\
\hline BcW1-SADW1 & 0.05 & 0.05 & 0.03 & 0.04 & -0.02 \\
\hline PcW1-GADW1 & $0.12^{* *}$ & $0.16^{* *}$ & $0.19^{* *}$ & $0.24^{* *}$ & 0.11 \\
\hline PcW1-SADW1 & $0.12 * *$ & $0.14 * *$ & $0.14 * *$ & $0.19 *$ & 0.02 \\
\hline \multicolumn{6}{|l|}{ Stability paths } \\
\hline $\mathrm{BcW} 1-\mathrm{BcW} 2$ & $0.37^{* *}$ & $0.20^{* *}$ & $0.37^{* *}$ & $0.44^{* *}$ & $0.47^{* *}$ \\
\hline $\mathrm{BcW} 2-\mathrm{BcW} 3$ & $0.55^{* *}$ & $0.43^{* *}$ & $0.46^{* *}$ & $0.60^{* * *}$ & $0.62^{* *}$ \\
\hline PcW1-PcW2 & $0.35^{* *}$ & $0.20^{* *}$ & $0.34^{* *}$ & $0.49^{* *}$ & $0.50^{* *}$ \\
\hline PcW2-PcW3 & $0.47 * *$ & $0.36^{* *}$ & $0.45^{* *}$ & $0.46^{* * *}$ & $0.64^{* *}$ \\
\hline GADW1-GADW2 & $0.35^{* *}$ & $0.20^{* *}$ & $0.34 * *$ & $0.49 * *$ & $0.50 * *$ \\
\hline GADW2-GADW3 & $0.62 * *$ & $0.46 * *$ & $0.61 * *$ & $0.64 * *$ & $0.72 * *$ \\
\hline SADW1-SADW2 & $0.42 * *$ & $0.35 * *$ & $0.47 * *$ & $0.39 * *$ & $0.49 * *$ \\
\hline SADW2-SADW3 & $0.46 * *$ & $0.34 * *$ & $0.51 * *$ & $0.38 * *$ & $0.59 * *$ \\
\hline \multicolumn{6}{|l|}{ Cross paths } \\
\hline BcW1-GADW2 & $0.07 * *$ & 0.06 & $0.10^{*}$ & $0.21 * *$ & 0.02 \\
\hline GADW1-BcW2 & $0.07 *$ & $0.13 * *$ & 0.04 & 0.15 & $0.14 *$ \\
\hline BcW2-GADW3 & $0.08 * *$ & $0.13 * *$ & $0.10^{*}$ & 0.12 & 0.11 \\
\hline GADW2-BcW3 & $0.07 *$ & 0.06 & $0.11 *$ & $0.19 *$ & 0.10 \\
\hline BcW1-SADW2 & $0.06^{*}$ & 0.04 & 0.04 & 0.05 & 0.06 \\
\hline SADW1-BcW2 & $0.14 * *$ & $0.13 * *$ & $0.10 *$ & 0.05 & $0.16^{*}$ \\
\hline BcW2-SADW3 & $0.12 * *$ & $0.11^{*}$ & $0.09 *$ & 0.01 & $0.02 * *$ \\
\hline SADW2-BcW3 & $0.12 * *$ & 0.06 & -0.01 & $0.25 * *$ & $0.23 * *$ \\
\hline PcW1-GADW2 & 0.04 & $0.12 *$ & 0.05 & $0.22 * *$ & 0.06 \\
\hline GADW1-PcW2 & $0.11 * *$ & $0.15 * *$ & $0.14 * *$ & $0.21 * *$ & $0.25 * *$ \\
\hline PcW2-GADW3 & 0.05 & $0.12 * *$ & $0.11 * *$ & 0.14 & $0.23 * *$ \\
\hline GADW2-PcW3 & $0.20 * *$ & $0.25 * *$ & $0.23 * *$ & $0.28 * *$ & $0.25 * *$ \\
\hline PcW1-SADW2 & $0.07 *$ & $0.13 * *$ & 0.07 & $0.18^{*}$ & -0.03 \\
\hline SADW1-PcW2 & $0.16^{* *}$ & $0.16 * *$ & $0.14 * *$ & $0.19^{*}$ & $0.24 * *$ \\
\hline PcW2-SADW3 & $0.09 * *$ & $0.12 * *$ & $0.15 * *$ & 0.14 & $0.15^{*}$ \\
\hline SADW2-PcW3 & $0.16^{* *}$ & $0.20 * *$ & 0.09 & $0.32 * *$ & $0.16^{*}$ \\
\hline
\end{tabular}

$W 1, W 2, W 3$ wave 1, wave 2, wave 3, Bc behavioral control, $P c$ psychological control, $G A D$ generalized anxiety disorder, $S A D$ separation anxiety disorder

$* p<0.05 ; * * p<0.01$

adolescent girls and the late adolescent boys. With regard to the cross paths between the constructs, results revealed that behavioral control on the first wave only significantly predicted GAD symptoms on the second wave for late adolescent boys. GAD on the first wave predicted behavioral control on the second wave for early adolescent boys and late adolescent girls. The association between behavioral control from the first wave to GAD on the second wave for late adolescent boys was as strong as the association between GAD on the first wave to behavioral control on the second wave for the late adolescent girls.
Initial correlations and cross paths of behavioral control and SAD symptoms

The initial correlations between behavioral control and SAD symptoms were not significant for the total adolescent group or any of the adolescent age and sex cohorts. Inspection of the cross paths revealed that a unidirectional pattern emerged; adolescents' SAD symptoms on one wave consistently had a significant influence on perceived parental behavioral control on the next wave. From the first wave to the second wave, this applied to the total adolescent group, the early adolescent boys, early adolescent girls 


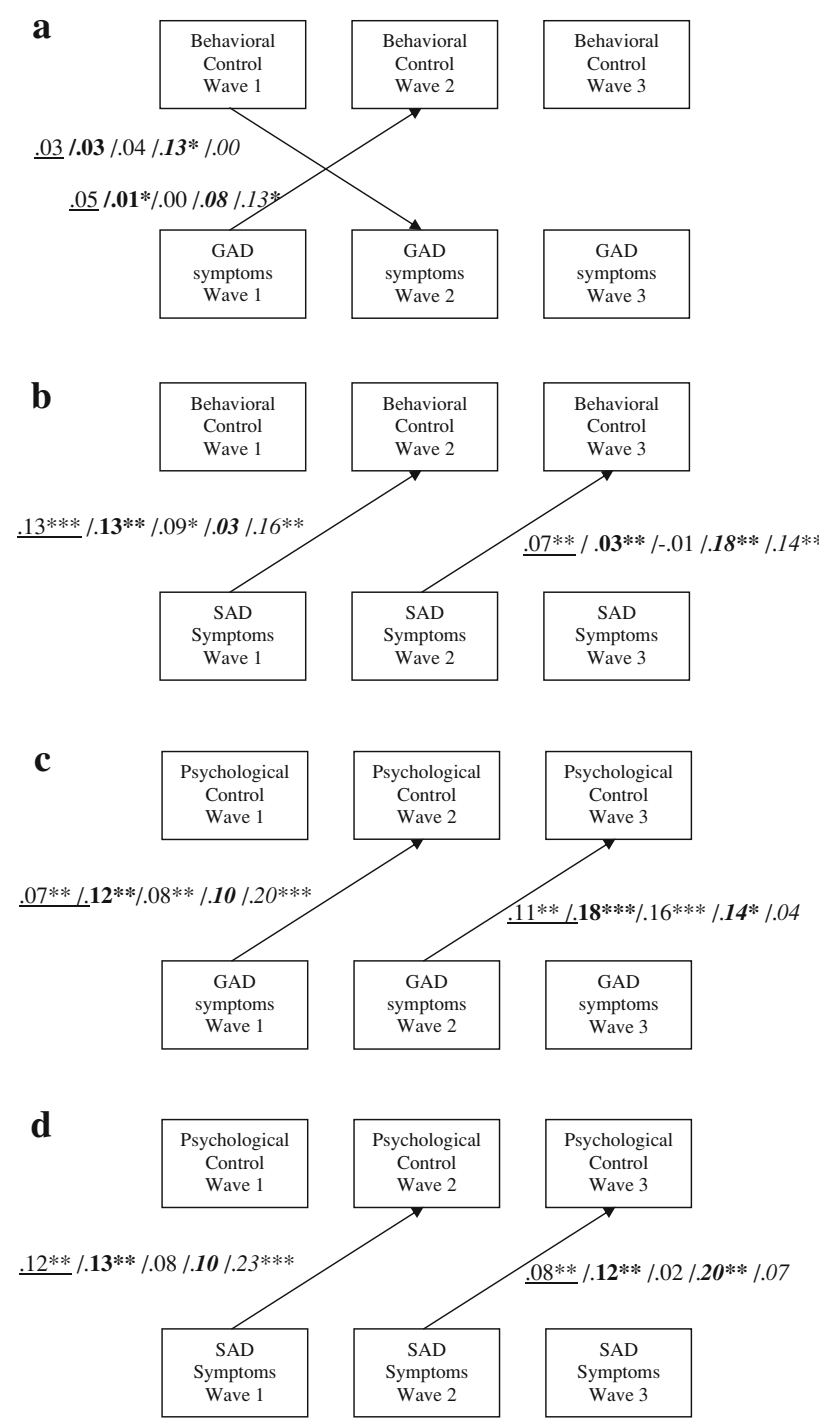

Fig. 1 a Standardized estimates of the statistically significant cross paths in a three-wave path model for adolescent-reported parental behavioral control and adolescent GAD symptoms for the total adolescent group and for all four age-sex groups, early boys, early girls late boys and late girls. *p $<0.05$; ** $p<$ $0.01 ; * * * p<0.001$. All stability paths are significant. The complete overview of the results can be obtained from the first author. b Standardized estimates of the statistically significant cross paths in a three-wave path model for adolescent-reported parental behavioral control and adolescent SAD symptoms for the total adolescent group and for all four age-sex groups, early boys, early girls, late boys and late girls. $* p<0.05 ; * * p<0.01$; $* * * p<0.001$. c Standardized estimates of the statistically significant cross paths in a three-wave path model for adolescentreported parental psychological control and adolescent GAD symptoms for the total adolescent group and for all four agesex groups, early boys, early girls, late boys and late girls. $* p<0.05 ; * * p<0.01 ; * * * p<0.001$. d Standardized estimates of the statistically significant cross paths in a three-wave path model for adolescent-reported parental psychological control and adolescent SAD symptoms for the total adolescent group and for all four age-sex groups, early boys, early girls, late boys and late girls. $* p<0.05 ; * * p<0.01 ; * * * p<0.001$ and late adolescent girls. From the second wave to the third wave, this pattern concerned the total adolescent group, early adolescent boys, the late adolescent boys with the strongest association and late adolescent girls.

Initial correlations and cross paths of psychological control and GAD symptoms

Initial correlations on the first wave for psychological control and GAD symptoms were positive and significant for the total adolescent group, early adolescent boys, early adolescent girls and late adolescent boys. The cross paths demonstrated a clear unidirectional pattern; GAD on the first wave predicted psychological control on the second wave and GAD on the second wave predicted psychological control on the third wave for both the total adolescent group and the early adolescent boys and girls. From the first wave (GAD) to the second wave (psychological control), this pattern also occurred for the total adolescent group and the late adolescent girls; from the second wave to the third wave this pattern also occurred for the late adolescent boys.

Initial correlations and cross paths of psychological control and SAD symptoms

Initial correlations on the first wave were positive and significant for the total adolescent group, early adolescent boys, early adolescent girls and late adolescent boys. The cross paths showed a specific unidirectional pattern from SAD symptoms to psychological control for the total adolescent group and the early adolescent boys. From the first wave to the second wave, the cross path was also significant for late adolescent girls.

\section{Discussion}

The purpose of the current study was to investigate the direction of effects between perceived parental behavioral and psychological control, and adolescent self-reported GAD and SAD symptoms, and to explore age and sex differences.

\section{Effect models}

The results of this study overall demonstrate a clear pattern of a unidirectional effect model, specifically a child effect model $[25,43]$ to describe the data. This child effect model demonstrates that adolescents with high initial levels of self-reported anxiety symptoms perceive their parents as becoming more controlling over time. This finding may be interpreted in two ways. The first interpretation is that 
adolescents suffering from anxiety symptoms perceive more controlling behaviors from their parents. This finding is in agreement with previous studies of cognitive biases of individuals with anxiety symptoms [3, 59]. Riskind and Williams [57] suggested that a dysfunctional looming cognitive style (LCS) might best describe individuals with anxiety symptoms. The LCS assumes that the generation of harm-related scenarios and appraisals leads to cognitions (e.g., worry) that activate specific behavioral responses [58]. For individuals with GAD symptoms, systematic biases have been found in the ways these individuals interpret ambiguous events, report threat-related automatic thoughts and process threat-related information [16, 57].

A second possibility is that parents of adolescents reporting anxiety symptoms actually change their behaviors and become more controlling toward their adolescents with self-reported anxiety symptoms. According to the child effect model, a child's characteristics are influential in shaping parental behavior [17, 18]. Adolescents with GAD or SAD symptoms may elicit parental behavioral control and parental psychological control as the parents try to prevent stress while adapting to the sensitivity of their adolescent in specific situations. In previous studies, it has been suggested that, in general, negative emotional problems of adolescents could easily lead to negative emotional responses of their parents [2,60]. More specifically, negative appeals from adolescents with GAD or SAD symptoms can lead to parents becoming less sensitive and more demanding (through behavioral control and psychological control) [21, 56].

Perceived parental psychological control and adolescent anxiety symptoms

With respect to the child effect model, adolescent GAD and SAD symptoms are stronger and more systematically associated with parental psychological control than with parental behavioral control. Adolescents with self-reported GAD and SAD symptoms perceive their parents as becoming increasingly psychologically controlling over time. The finding of significant associations between psychological control and adolescent anxiety is in agreement with previous cross-sectional studies [35, 55]. This specific connection between parental psychological control and anxiety as internalizing problem behavior could stem from a cognitive bias that make adolescents with anxiety symptoms perceive their parents as more psychologically controlling [3].

Age and sex differences

The exploration of age and sex differences demonstrated that for the early adolescents, the child effects were stronger for the boys; for the late adolescents, the child effects did not differ between boys and girls. This finding is partly in agreement with a longitudinal study, demonstrating that the influence of the cognitive bias of perceived negative parental behaviors, such as parental control, decreases over time for adolescent boys, whereas for adolescent girls their sensitivity to perceived negative parental behaviors increases [35].

\section{Possible treatment implications}

The results of this study can have some practical implications for the treatment of adolescents with anxiety symptoms and their parents. With respect to adolescents with GAD and SAD symptoms, the American Academy of Child and Adolescent Psychiatry indicates that the Multimodal Treatment Approach [4] should be the first choice in treating adolescents with anxiety symptoms. Cognitivebehavioral therapy (CBT) has been indicated as the first choice for anxious youth [1, 24, 66, 82]. Studies comparing family-focused (FCBT) and child-focused (CCBT) interventions demonstrated that both approaches led to ongoing reductions in child anxiety. Recently, support has been found for an advantage of a FCBT program above a CCBT program for child and early adolescent anxiety disorder symptoms in a 1-year follow-up design [82]. This line of research is ongoing.

With respect to specific therapy findings for adolescent SAD, it has been shown that for adolescents with SAD symptoms, interventions that improve parent-child interactions and teach parenting skills that reinforce the adolescent's positive adaptive coping and stimulate developmental-appropriate behavior and autonomy are important ingredients in successful treatment [4]. Additionally, based on the results of this study, we would suggest treatment should also be supplemented with parental psycho-education, since adolescents with SAD symptoms perceive an increase of parental controlling behaviors over time.

As to adolescent GAD, reviews of specific GAD treatment outcome research indicated that CBT as a part of the Multimodal Treatment Approach is the first choice of all other treatments [e.g., 1, 24]. Several studies have indicated that especially for late adolescents, the integration of CBT with a family component $[15,33,71]$ or CBT in a combination with interpersonal therapy [23] is advisable. In light of our findings, we would suggest that specific attention should also be paid to the adolescent's perception of parental control in the parent-adolescent interaction. This is important since it is known that for adolescents with GAD symptoms, and especially for late adolescent girls, the quality of their relationships forms a central theme in their frequent and excessive worry [35, 38]. 


\section{Limitations}

In terms of the limitations of this study, it should be first noted that the research sample only comprised adolescents from the general population. Nevertheless, research in community populations can provide insight into developmental issues relevant to the clinical setting [35].

Secondly, when interpreting the results, it is important to bear in mind that perceived adolescent GAD and SAD symptoms were assessed by self-report. When we refer, for instance, to adolescent GAD symptoms, we are speaking of self-reported GAD symptoms. In the field of research on adolescent anxiety, the adolescent self-report has been widely accepted for use [36, 72]. However, this should not be confused with a clinical diagnosis of an anxiety disorder. Additionally, parental behavioral control and parental psychological control were also assessed by the use of adolescent self-reports. Recently, it has been suggested that adolescents are able to distinguish when their parents are controlling their activities [8, 50, 67]. Nevertheless, since parental reports of their own parenting behaviors were not included in the current study, it cannot be said for sure whether the adolescent perception is in agreement with actual parental behaviors or if adolescent anxiety symptoms play a role in the evaluation of parental behaviors.

Furthermore, in this study, attention is only given to both parents as a unit, rather than focusing attention on the father and the mother separately. It is possible that adolescent boys and girls respond in a different way to their mothers and fathers. Additionally, it is also possible that parents' gender socialization influences eventual differences in their controlling behaviors [8]. A multi-informant perspective could be used in future studies of adolescent anxiety and parental control to help judge the findings of this study.

In the current study, behavioral control has been measured by the CRPBI subscale 'behavioral control'. According to the recent theoretical insights [34, 69, 77], the ambiguous interpretation of the term control in behavioral control is visible in the CRPBI subscale 'behavioral control' $[63,69]$ used in this study. It is unclear whether the positive associations between behavioral control and adolescent GAD and SAD symptoms were exactly driven by structure and regulation, by pressuring parenting, or by both. The suggestion to develop distinguished measures of parental regulation and structure, on the one hand, and control, on the other hand, will definitively refine the measurements of parenting dimensions $[34,69,76]$.

The positive relationship between parental psychological control and depression as internalizing problem behavior has been demonstrated in a longitudinal design [68]. It is conceivable that depression also plays a role in the relationship between parental psychological control and adolescent anxiety. Therefore, future longitudinal research to explore the relationship between psychological control and co-occurring symptoms of adolescent anxiety and depression may provide new insights.

\section{Summary}

To conclude, the current study demonstrates a clear unidirectional child effect model in the relationship between adolescent GAD and SAD symptoms and perceived parental behavioral control and parental psychological control. In other words, adolescents suffering from anxiety symptoms perceive their parents as becoming increasingly controlling, less sensitive and more demanding over time. Additionally, it was found that adolescent GAD and SAD symptoms are stronger and more systematically related to psychological control than to behavioral control possibly due to a cognitive bias on the part of the adolescent. With regard to the exploration of age and gender differences, GAD and SAD symptoms almost systematically predicted parental control over time for the early adolescent boys, whereas no significant differences were found for the late adolescents. The findings of the current study may indicate that adolescents with GAD and SAD symptoms might need specific psychotherapy focused on restructuring the adolescent's perception of the parent-adolescent relationship, as well as the need for parental psycho-education in the context of the Multimodal Treatment Approach.

\section{Conflict of interest None.}

Open Access This article is distributed under the terms of the Creative Commons Attribution Noncommercial License which permits any noncommercial use, distribution, and reproduction in any medium, provided the original author(s) and source are credited.

\section{References}

1. Albano AM, Kendall PC (2002) Cognitive behavioral therapy for children and adolescents with anxiety disorders: clinical research advances. Int Rev Psychiatry 14:129-134

2. Albrecht AK, Galambos NL, Jansson SM (2007) Adolescents' internalizing and aggressive behaviors and perceptions of parents' psychological control: a panel study examining direction of effects. J Youth Adolesc 36:673-684

3. Alloy LB, Riskind JH (eds) (2006) Cognitive vulnerability to emotional disorders. Erlbaum, New York

4. American Academy of Child and Adolescent Psychiatry (2007) AACAP official action; practice parameter for the assessment and treatment of children and adolescents with anxiety disorders. J Am Ac Child Adolesc Psychiatry 46:267-283

5. American Psychiatric Association (2000) Diagnostic and statistical manual of mental disorders, 4th edn, Text Revision (DSMIV-TR) American Psychiatric Association, Washington

6. Andrews MD, Hobbs MJ, Borkovec TD, Beesdo K, Graske MG, Heimberg RG et al (2010) Generalized worry disorder: a review 
of DSM-IV generalized anxiety disorder and options for DSM-V. Depress Anxiety 27:134-147

7. Arbuckle JL, Wothke W (2006) AMOS 7.0 user's guide. SmallWaters, Chicago

8. Arim RG, Marshall SK, Shapka JD (2010) A domain-specific approach to adolescent reporting of parental control. J Adolesc 33:355-366

9. Ballash N, Leyfer O, Buckley AF, Woodruff-Borden J (2006) Parental control in the etiology of anxiety. Clin Child Fam Psychol Rev 9:113-133

10. Barber BK (1996) Parental psychological control: revisiting a neglected construct. Child Dev 67:3296-3319

11. Barber BK, Harmon EL (2002) Violating the self: parental psychological control of children and adolescents. In: Barber BK (ed) Intrusive parenting: how psychological control affects children and adolescents. APA, Washington DC, pp 15-52

12. Barber BK, Olsen JE, Shagle SC (1994) Associations between parental psychological and behavioural control and youth internalized and externalized behaviors. Child Dev 65:1120-1136

13. Barber BK, Stolz HE, Olsen JA (2005) Parental support, psychological control, and behavioural control: assessing relevance across time, method, and culture. Monogr Soc Res Child Dev 70(282):1-137

14. Barlow DH (2002) Anxiety and its disorders: the nature and treatment of anxiety and panic, 2nd edn. Guilford Press, New York

15. Barmish A, Kendall P (2005) Should parents be co-clients in cognitive- behavioural therapy for anxious youth? J Clin Child Adolesc Psychol 34(3):569-581

16. Beck AT, Clark DA (1997) An information processing model of anxiety: automatic and strategic processes. Behav Res Ther 35:49-58

17. Bell RQ, Chapman M (1986) Child effects in studies using experimental or brief longitudinal approaches to socialization. Dev Psychol 22:595-603

18. Belsky J (1984) The determinants of parenting. A process model. Child Dev 55:83-97

19. Birmaher B, Brent DA, Chiappetta L, Bridge J, Monga S, Baugher M (1999) Psychometric properties of the screen for child anxiety related emotional disorders (SCARED): a replication study. J Am Ac Child Adolesc Psychiatry 38:1230-1236

20. Birmaher B, Khetarpal S, Brent D, Cully M, Balach L, Kaufman J, McKenzie-Neer S et al (1997) The screen for child anxiety related emotional disorders (SCARED): scale construction and psychometric characteristics. J Am Ac Child Adolesc Psychiatry 36:533-545

21. Bögels SM, Brechman-Toussaint ML (2006) Family issues in child anxiety: attachment, family functioning, parental rearing and beliefs. Clin Psychol Rev 26:834-856

22. Bollen L (1989) Structural equations with latent variables. Wiley, New York

23. Borkovec TD, Newman MG, Pincus AL, Lytle R (2002) A component analysis of cognitive-behavioral therapy for generalized anxiety disorder and the role of interpersonal problems. J Consult Clin Psychol 70:288-298

24. Borkovec TD, Ruscio A (2000) Psychotherapy for generalized anxiety disorder. J Clin Psychiatry 62:37-45

25. Branje SJT, Hale WW III, Meeus WHJ (2008) Reciprocal development of parent-adolescent support and adolescent problem behaviors. In: Kerr M, Stattin H, Engels R (eds) What can parents do? New insights into the role of parents in adolescent problem behaviour. Wiley, Chichester, pp 135-162

26. Chorpita BF, Barlow DH (1998) The development of anxiety: the role of control in the early development. Psychol Bull 124:321
27. Chorpita BF, Brown TS, Barlow DH (1998) Perceived control as a mediator of family environment in etiological models of childhood anxiety. Beh Ther 29:457-476

28. Cobham VE, Dadds MR, Spence SH (1999) Anxious children and their parents: what do they expect? J Clin Child Psychol 28:220-231

29. Costello EJ, Mustillo S, Erkanli A, Keeler G, Angold A (2003) Prevalence and development of psychiatric disorders in childhood and adolescence. Arch Gen Psychiatry 54:329-336

30. Cronk NJ, Slutske WS, Madden PAF, Bucholz KK, Heath AC (2004) Risk for separation anxiety disorder among girls: paternal absence, socioeconomic disadvantage, and genetic vulnerability. J Abn Psychol 113:237-247

31. Dadds MR (2002) Learning and intimacy in the families of anxious children. In: McMahon RJ, Peters RD (eds) The effects of parental dysfunction on children. Kluwer Academic/Plenum, New York, pp 87-104

32. Dadds MR, Barrett PM, Rapee RM, Ryan S (1996) Family process and child anxiety and aggression: an observational analysis. J Abn Child Psychol 24:715-734

33. Diamond G, Josephson A (2005) Family based treatment research: a 10-year update. J Am Ac Child Adolesc Psychiatry 44(9):872-887

34. Grolnick WS, Pomerantz EM (2009) Issues and challenges in studying parental control: toward a new conceptualization. Child Dev Perspect 3:165-170

35. Hale WW III, Engels R, Meeus W (2006) Adolescent's perceptions of parenting behaviors and its relationship to adolescent generalized anxiety disorder symptoms. J Adolesc 29:407-417

36. Hale WW III, Raaijmakers Q, Muris P, van Hoof A, Meeus W (2008) Developmental trajectories of adolescent anxiety disorder symptoms: a 5-year prospective community study. J Am Ac Child Adolesc Psychiatry 47:557-565

37. Hale WW III, Raaijmakers Q, Muris P, Meeus W (2005) Psychometric properties of the screen for child anxiety related emotional disorders (SCARED) in the general adolescent population. J Am Ac Child Adolesc Psychiatry 44:283-290

38. Hankin BL, Abramson LY (2001) Development of gender differences in depression: an elaborated cognitive vulnerability transactional stress theory. Psychol Bull 127:773-796

39. Hudson JL, Rapee RM (2004) From anxious temperament to disorder. In: Heimberg RG, Turk CL, Mennin DS (eds) Generalized anxiety disorder: advances in research and practice. The Guilford Press, New York, pp 51-74

40. Kawash GF, Clewes JL (1988) A factor analysis of a short form of the CRPBI: are children's perceptions of control and discipline multidimensional? J Psychol 122:57-67

41. Kerr M, Stattin H (2003) Parenting of adolescents: action or reaction? In: Crouter AC, Booth A (eds) Children's influence on family dynamics: the neglected side of family relationships. Erlbaum, New York, pp 121-151

42. Kline RB (2005) Principles and practice of structural equation modeling. Guildford Press, New York

43. Lollis S, Kuczynski L (1997) Beyond one hand clapping: seeing bidirectonality in parent-child relations. J Soc Pers Rel 14:441-461

44. McLeod BD, Wood JJ, Weisz JR (2007) Examining the association between parenting and childhood anxiety: a meta-analysis. Clin Psychol Rev 27:155-172

45. Meeus W, Akse J, Branje SJT et al (2004) Codeboek van het onderzoeksproject CONflicts And Management Of RElationships (CONAMORE). Eerste meetronde: 2001. [Codebook of the research project CONflicts And Management Of RElationships (CONAMORE) First wave: 2001.] Unpublished manuscript, Utrecht University, The Netherlands. 
46. Muris P, Meesters C, Merckelbach H, Huelsenbeck P (2000) Worry in children is related to perceived parental rearing and attachment. Beh Res Ther 38:487-497

47. Muris P, Meesters C, Van Melick M, Zwambag L (2001) Self reported attachment style, attachment quality, and symptoms of anxiety and depression in young adolescents. Pers Individ Dif 30:809-818

48. Muris P, Merckelbach H (1998) Perceived parental rearing behavior and anxiety disorders symptoms in normal children. Pers Individ Dif 25:1199-1206

49. Myers K, Winters NC (2002) Ten-year review of rating scales. II: scales for internalizing disorders. J Am Ac Child Adolesc Psychiatry 41:634-659

50. Padilla-Walker LM, Carlo G (2003) "It's not fair!" Adolescents' constructions of appropriateness of parental reactions. J Youth Adolesc 33:389-401

51. Patterson GR (1982) A social learning approach: III. Coercive family process. Castalia, Eugene

52. Parker G (1993) Parental overprotection: a risk factor in psychosocial development. Grune and Stratton, New York

53. Pettit GS, Laird RD, Dodge KA, Bates JE, Criss MM (2001) Antecedents and behavior-problem outcomes of parental monitoring and psychological control in early adolescence. Child Dev 72:583-598

54. Rapee RM (1991) Generalized anxiety disorder: a review of clinical features and theoretic concepts. Clin psychol Rev $11: 419-440$

55. Rapee RM (1997) Potential role of childrearing practices in the development of anxiety and depression. Clin Psychol Rev 7:47-67

56. Rapee RM (2001) The development of generalized anxiety. In: Vasey MW, Dadds MR (eds) The developmental psychopathology of anxiety. Oxford University Press, London, pp 481-503

57. Riskind JH, Williams NL (2005) The looming cognitive style and generalized anxiety disorder: distinctive danger schemas and cognitive phenomenology. Cognit Ther Res 29:7-27

58. Riskind JH, Tzur D, Williams NL, Mann B, Shahar G (2007) Short-term predictive effects of the looming cognitive style on anxiety disorder symptoms under restrictive methodological conditions. Behav Res Ther 45:1765-1777

59. Riskind JH, Williams NL, Joiner TE Jr (2006) The looming cognitive style: a cognitive vulnerability for anxiety disorders. J Soc Clin Psychol 25:779-801

60. Rogers KN, Buchanan CM, Winchell ME (2003) Psychological control during early adolescence: links to adjustment in differing parent/adolescent dyads. J Early Adolesc 23:349-383

61. Rubin KH, Mills RSL (1991) Conceptualizing developmental pathways to internalizing disorders in childhood. Can J Behav Sci 23:300-317

62. Sameroff AJ (1983) Developmental systems: contexts and evolution. In: Kessen W (ed) Handbook of Child Psychology, 4th edn. Wiley, New York, pp 237-294

63. Schaefer ES (1965) Children's reports of parental behavior: an inventory. Child Dev 36:413-424

64. Schaefer ES (1965) A configurational analysis of children's reports of parent behavior. J Cons Psychol 20:552-557

65. Schwarz JC, Barton-Henry ML, Pruzinsky T (1985) Assessing child-rearing behaviors: a comparison of ratings made by mother, father, child, and sibling on the CRPBI. Child Dev 56:462-479

66. Silverman W, Kurtines W, Ginsberg G, Weems C, Lumpkin P, Carmichael D (1999) Treating anxiety disorders in children with Group cognitive behaviour therapy: a randomized clinical trial. J Consult Clin Psychol 76:995-1003
67. Smetana JG, Daddis C (2002) Domain-specific antecedents of parental psychological control and monitoring: The role of parenting beliefs and practices. Child Dev 73:563-580

68. Soenens B, Luyckx K, Vansteenkiste M, Duriez B, Goossens L (2008) Clarifying the link between parental psychological control and adolescents' depressive symptoms. Reciprocal versus unidirectional models. Merrill-Palmer Q 54:411-444

69. Soenens B, Vansteenkiste M (2010) A theoretical upgrade of the concept of parental psychological control: proposing new insights on the basis of self-determination theory. Dev Rev 30:74-99

70. Soenens B, Vansteenkiste M, Luyten DuriezB, Goossens L (2005) Maladaptive perfectionistic self-representations: the mediational link between psychological control and adjustment. Pers Individ Dif 38:487-498

71. Southam-Gerow MA, Kendall PC, Weersing VR (2001) Examining outcome variability: correlates of treatment response in a child and adolescent clinic. J Clin Child Psychol 30:422-436

72. Stallings P, March JS (1995) Assessment. In: March JS (ed) Anxiety disorders in children and adolescents. Guilford, New York, pp 125-147

73. Stattin H, Kerr M (2000) Parental monitoring: a reinterpretation. Child Dev 71:1072-1085

74. Van Brakel AML, Muris P, Bögels SM, Thomassen C (2006) A multifactorial model for the etiology of anxiety in non-clinical adolescents: main and interactive effects of behavioral inhibition, attachment and parental rearing. J Child Fam Stud 15:569-579

75. Verhulst FC, Van der Ende J, Ferdinand RF, Kasius MC (1997) The prevalence of DSM-III-R diagnoses in a national sample of Dutch adolescents. Arch Gen Psychiatry 54:329-336

76. Wang Q, Pomerantz EM, Chen HC (2007) The role of parents' control in early adolescents' psychological functioning: a longitudinal investigation in the United States and China. Child Dev 78:1592-1610

77. Warren S, Sroufe LA (2004) Developmental Issues. In: Ollendick $\mathrm{T}$, Marsh J (eds) Phobic and anxiety disorders in children and adolescents: a clinican's guide to effective psychosocial and pharmacological intervention. Oxford University Press, New York, pp 92-115

78. Weems CF, Costa NM (2005) Developmental differences in the expression of childhood anxiety symptoms and fears. J Am Ac Child Adolesc Psychiatry 44:656-663

79. Weems CF, Silverman WK, La Greca AM (2000) What do youth referred for anxiety problems worry about? Worry and its relation to anxiety and anxiety disorders in children and adolescents. J Abn Child Psychol 28:63-72

80. Weems CF, Stickle TR (2005) Anxiety disorders in childhood: casting a nomological net. Clin Child Fam Psychol Rev 8:107-134

81. Westenberg PM, Drewes MJ, Siebelink BM, Treffers PDA (2004) A developmental analysis of self-reported fears in late childhood through mid-adolescence: social-evaluative fears on the rise? J Child Psychol Psychiatry Allied Disc 45:481-496

82. Wood JJ, McLeod BD, Piacentini JC, Sigman M (2009) One-year follow-up of family versus child CBT for anxiety disorders: exploring the roles of child age and parental intrusiveness. Child Psychiatry Human Dev 40:301-316

83. Wood JJ, McLeod BD, Sigman M, Hwang W-C, Chu BC (2003) Parenting and childhood anxiety: theory, empirical findings, and future directions. J Child Psychol Psychiatry 44:134-151

84. Woodruff-Borden J, Morrow C, Bourland S, Cambron S (2002) The behavior of anxious parents: examining mechanisms of transmission of anxiety from parent to child. J Clin Child Adolesc Psychol 31:364-374 